\title{
Biochemical Changes in Analysis Indicators are the Result of Special Tests of Freestyle Wrestlers about Alactate and Lactate
}

\author{
Dao Chanh Thuc* and Vang Cong Danh \\ Physical Education Department, A Giang University, Vietnam
}

Submission: October 04, 2018; Published: October 17, 2018

*Corresponding author: Dao Chanh Thuc, Physical Education Department, A Giang University, Vietnam, Email: thuchus@gmail.com

\begin{abstract}
The paper presents a pattern of alactic, lactic and mixed types of freestyle wrestlers identified using the cluster analysis (computer application SPSS 20.0) of biochemical parameters growth of alactic (creatinine) and lactic (lactic acid) anaerobic energy supply mechanisms in response to specific check tests. The study involved 29 freestyle wrestlers with classification from I degree to Master of Sports (4-9 years of experience in training). It has been established that 6 athletes belong to alactic, 9 to lactic and 14 athletes to mixed types, which made it possible to customize the training program.
\end{abstract}

Keywords: Freestyle Wrestlers; Cluster Analysis; Biochemical Monitoring; Special Check Test

\section{Introduction}

The physical fitness of wrestlers they show during a competitive fight, particularly depends on the capacity of maximum mobilization of anaerobic (lactic and alactic) energy systems against the backdrop of well-developed respiratory phosphorylation (aerobic energy-supply component) M Sybil [1]. The studies that would scientifically justify the individual approach to adjustment of training sessions of skilled wrestlers in terms of peculiarities of their energy supply systems are few and declarative in nature like classical identification of biochemical parameters in response to physical exertion of wrestlers M Sybil [1]. Targeted improvement of aerobic and anaerobic components of energy supply is usually carried out under the scheme of combining different modes of physical training. However, the issue of regulation of physical activity depending on physical fitness and individual development of energy supply mechanisms of an athlete still remains controversial and insufficiently studied Oleg Koptev [2], Adu Makhalin [3], Sybil MH, [4], Boyko VF [5], Sorvanov VA [6].

Scientific sources highlight the issues of percentage ratio of aerobic and types of anaerobic components of energy supply that varies at different stages of physical fitness, but within the analyzed literature we have not found any results of individually targeted influence on specific components of anaerobic energy exchange in freestyle wrestlers Latyshev Mykola [7]. Preliminary analysis has justified the relevance of scientific research in finding pattern characteristics of skilled freestyle wrestlers according to their belonging to anaerobic alactic, anaerobic lactic or balanced (mixed alactic-lactic) types.

\section{Materials and Methods}

It has been suggested to perform ranking of all participants of the experiment by the depth of biochemical shifts in response to a special check load using cluster analysis - Hierarchical Cluster Analysis (HCA), SPSS. Cluster analysis-is a set of multivariate statistical procedures, which allows arranging objects by homogeneous groups. The software system HCA with the help of the cluster analysis divided the examined set of objects, represented as a matrix "objects-properties" into homogeneous groups using some degree of similarity between the objects "squared Euclidean distance". The algorithm of cluster analysis belongs to agglomerative procedures that firstly unite the nearest objects into the groups and then add more distant ones Thuc DC [8]. SPSS 20.0 software was used to conduct cluster analysis Boyko VF [5]. It should be noted that the muscular efforts of skilled freestyle wrestlers are directly dependent on the state of anaerobic energy system development, which consists of the two components - alactic and lactic one.

The first component of ATP resynthesis has creatine phosphokinase origin and the process of its implementation during muscle loads is accompanied by adequate accumulation of creatinine in urine with regard to degree of its involvement $\mathrm{M}$ Sybil [9]. The second lactic component has glycolytic origin. This ATP resynthesis leads to accumulation of lactic acid in urine, i.e. lactate. Thus, better involved alactic component is characterized by greater shifts in creatinine excretion. While increased excretion of lactic acid occurs in athletes with more powerful mobilization of glycolytic resource M Sybil [8]; Thuc DC [8]. 


\section{Results}

29 freestyle wrestling athletes participated in the experiment. Their content of lactic acid and creatinine was determined before and after special check tests. Having applied the cluster analysis according to indicators of creatinine and lactic acid all athletes were divided into 3 clusters i.e. similarity groups (Table 1 ). It should be noted that the increase (in \%) of the studied parameters in athletes varies in a wide range, namely creatinine - 40.8 - 558.4 standard units, lactic acid - 47.5 - 199.3 standard units. This is connected with to the predominance of a component of anaerobic energy supply. Thus, the application referred 9 freestyle wrestlers to the first cluster with a predominant content of lactic acid. The second - 14 athletes with a balanced content of creatinine and lactic acid, the third- 6 wrestlers with a high content of creatinine (Tables 1 \& 2). The program determined the mean values of creatinine and lactic acid for each cluster and estimated the standard error of the arithmetic mean. With these values you can easily check the statistical essence of sampling arithmetic mean (M) for each cluster indicator. To do this, you should divide M by the corresponding standard error of the arithmetic mean and compare the resulting value $t$ with the corresponding table ("The value of coefficient $t$ for different levels of probability $\mathrm{p}$. Depending on the number of degrees of freedom") Adu Makhalin [3]. Having determined $t$, it has been found that the mean indicators of creatinine and lactic acid calculated by the program are true in different clusters, indicating to scientifically sound approach to the use of the cluster analysis for division of athletes into groups by predominance of some component of anaerobic energy supply.

Table 1: Results of cluster analysis in freestyle wrestlers after check tests.

\begin{tabular}{|c|c|c|c|}
\hline Wrestlers & Cluster & Wrestlers & Cluster \\
\hline A & 1 & K & 1 \\
B & 2 & L & 2 \\
C & 1 & M & 2 \\
D & 1 & N & 3 \\
E & 1 & O & 2 \\
F & 2 & P & 2 \\
G & 2 & Q & 3 \\
H & 2 & R & 3 \\
I & 2 & S & 2 \\
J & 1 & T & 3 \\
\hline
\end{tabular}

Table 2: Mean values of creatinine and lactic acid indicators in freestyle wrestlers after the check tests in different clusters.

\begin{tabular}{|c|c|c|c|c|c|c|}
\hline \multirow{2}{*}{ Statistical analysis in clusters } & \multicolumn{3}{|c|}{ Creatinine, mmol/l } & \multicolumn{3}{|c|}{ Lactic Acid, mmol/l } \\
\cline { 2 - 7 } & M & SD & P & M & SD & P \\
\hline 1 & 74.92 & 14.93 & $0.000^{*}$ & 165.89 & 8.71 & $0.000^{*}$ \\
\hline 2 & 78.09 & 8.02 & $0.000^{*}$ & 79.09 & 7.13 & $0.000^{*}$ \\
\hline 3 & 457.39 & 79.15 & $0.000^{*}$ & 93.77 & 21.19 & $0.000^{*}$ \\
\hline Summary results & 115.49 & 27.09 & & 107.84 & 8.64 & \\
\hline
\end{tabular}

To ensure the correctness, individual representatives organized into cluster groups by similarity of biochemical shifts of creatinine and lactic acid were given the names "lactics"-with the dominant glycolytic type of anaerobic energy supply (by the degree of closeness to the maximum displacement of lactic acid), "alactics"-with a dominant creatine phosphate type of anaerobic energy supply (by the degree of closeness to the maximum displacement of creatinine), and representatives of the "mixed" type with pronounced roughly equal shifts by the two biochemical parameters (Table 2). As it is easy to see, representatives of the first cluster are characterized by the highest displacements of lactic acid in response to the dosage test load and it is equal to 165.89 $\mathrm{mmol} / \mathrm{l}$. That is, the implementation of muscular effort was due to
ATP glycolytic origin. Therefore, the representatives of this group received the conditional name "lactate". In contrast, the athletes of the third cluster group realized muscular effort in the process of similar control testing with the participation of ATP creatine phosphokinase origin, and therefore entered the alactated group of athletes. This indicates the average creatinine displacement is equal to $457.39 \mathrm{mmol} / \mathrm{l}$. The mixed type (alacta-lactate) is represented by a second cluster of athletes who performed muscular work using ATP and glycolytic and creatine phosphokinase origin approximately equally, as can be seen from the mean values of displacements as lactate $(79.09 \mathrm{mmol} / \mathrm{l})$ and creatinine $(78.09$ $\mathrm{mmol} / \mathrm{l})$.

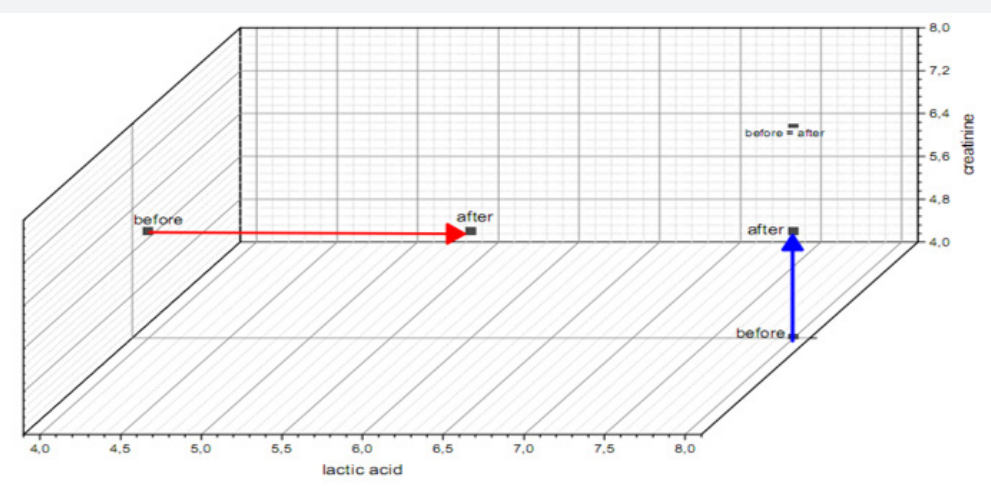

Figure 1: The impact of the program on individual pronounced individuals. 
In particular, it is easy to see on the model I the displacement of anaerobic energy exchange in the direction of the lactate vector, and vice versa, the second model example is a reflection of the improvement of the same anaerobic power supply mechanism with the increase in the weight of its alactated vector (Figure 1). The mixed type model (III) demonstrates the lack of qualitative changes in the orientation of the two vectors, since the influence on them was alternating (alactate-lactate) character. Therefore, both the anaerobic power supply units developed less pronounced but equally. It should be noted that after the special check tests the mixed type of anaerobic energy supply dominates in this group of athletes (Tables $1 \& 2$ ). The "alactics" among the freestyle wrestlers proved to be the least (only three out of twenty people). It is known that creatinine is the end product of nitrogenous metabolism. It is produced in muscle tissue from creatine phosphate M Sybil [9]. Daily creatinine excretion for every person is a fairly constant value and reflects the degree of involvement of creatine phosphokinase energy supply mechanism. This mechanism is responsible for the quality of instant actions and is the most difficult to train M Sybil [9]. Therefore, there were the least number of freestyle wrestlers with the "alactics" pattern and they had the lowest level of qualification (I degree) [10-14].

\section{Conclusion}

Based on the cluster analysis of biochemical parameters shifts we have determined pattern characteristics of alactic, lactic and mixed types, which allows developing the author's program of individualization of the training process of freestyle wrestlers. Thus, the results of cluster analysis can be used for adjustment of athletes training schemes to improve their fitness level by the principle of individualization according to the pattern energy series.

\section{References}

1. M Sybil (2018) Biochemical changes in cluster analysis indicators because of special tests of freestyle wrestlers of alactate and lactate types of power supply. Journal of Physical Education and Sport 18(1): 235-238.
2. Oleg Koptev (2017) Estimation degree of changes influence in competition rules on the contest's ratios of judo wrestlers of lightweight categories in Russia and Kyrgyzstan. Journal of physical education and sport. 17(4): 2067-2072.

3. Adu, Makhalin, Elena, Tokmasheva, Marina, et al. (2016) Anthropometric features of Altai Youth Sambo Wrestlers. Journal of physical education and sport 16(2): 489-492.

4. Sybil MH, Pervachuk RV, Chuiev AYu (2015) Targeted influence on anaerobic systems of energy supply of skilled freestyle wrestlers. Pedagogy, psychology, and medical-biological problems of physical education and sports 7: 48-58.

5. Boyko VF (2014) Competitive activities of highly-skilled freestyle wrestlers at the present stage. Physical education of students 4: 13-19.

6. Sorvanov VA, Alekseeva YuP (2005) Search for ways of measurement of special endurance. Theory and Practice of Physical Culture 3: 49-53.

7. Latyshev Mykola (2017) Performance analysis of freestyle wrestling competitions of the last olympic cycle 2013-16. Journal of physical education and sport 17(2): 590-594.

8. Chanh Thuc Dao (2018) Measurement in sports. LAP LAMBERT Academic Publishing, ISBN.

9. Sybil MG, Pervachuk RV, Trach VM (2015) Personalization of freestyle wrestlers' training process by influence the anaerobic systems of energy supply. Journal of physical education and sport. 15(2): 225-228.

10. Dao Chanh Thuc (2018) The influence of physical activities on biological age parameters of females from 17 to 18 years old. Sports Medicine and Therapy Journal pp. 075-079.

11. Dao Chanh Thuc (2018) The influence of physical activities on biological age parameters of the first-year female students from a Giang University-Vietnam. Biomedical Journal of Scientific \& Technical Research 7(2): 1-4.

12. Humetsky RYa (2004) Mathematical methods in biology: theoretical data, programmable practicum, computer tests. Lviv: Publishing center of Ivan Franko National University of Lviv pp. 112.

13. Medved AV (2009) Improvement of annual cycle of training of highlyskilled wrestlers. The world of sports 1: 3-6.

14. Sazonov V (2014) Characteristics of factors of fatigue of skilled athletes-combatants. Relevant Problems of Physical Culture and Sports 29(1): 68-74.

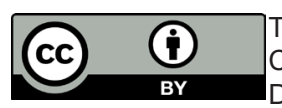

This work is licensed under Creative Commons Attribution 4.0 License DOI: 10.19080/JPFMTS.2018.05.555667

\section{Your next submission with Juniper Publishers} will reach you the below assets

- Quality Editorial service

- Swift Peer Review

- Reprints availability

- E-prints Service

- Manuscript Podcast for convenient understanding

- Global attainment for your research

- Manuscript accessibility in different formats

( Pdf, E-pub, Full Text, Audio)

- Unceasing customer service

Track the below URL for one-step submission

https://juniperpublishers.com/online-submission.php 